\title{
Pemetaan Parameter Oseanografi Fisik Menggunakan Citra Landsat 8 di Wilayah Perairan Nongsa Pulau Batam
}

\author{
Andriansyah Pratama Daya*, Muhammad Zainuddin Lubis" \\ "Mahasiswa Program Studi Teknik Geomatika Jurusan Teknik Informatika, Politeknik Negeri Batam \\ Jalan Ahmad Yani, Batam Centre, Batam 29461, Indonesia \\ E-mail: andriansyahpd@gmail.com \\ \#Dosen Program Studi Teknik Geomatika Jurusan Teknik Informatika, Politeknik Negeri Batam \\ Jalan Ahmad Yani, Batam Centre, Batam 29461, Indonesia \\ E-mail: zainuddinlubis@polibatam.ac.id
}

\begin{abstract}
Abstrak
Parameter oseanografi merupakan dinamika alam yang terjadi mempengaruhi aspek fisis air laut, seperti suhu, pasang surut dan arus .Penelitian ini mengambil sampel di wilayah perairan Nongsa, kemudian dilakukan pengolahan data dengan penginderaan jauh menggunakan algoritma Lyzenga dan mengambil data primer suhu,DO,arus dalam bentuk pola arus, pasang surut yang disajikan dalam bentuk grafik. Hasil yang di dapatkan di lapangan kecepatan arus di pantai Nongsa dengan kecepatan dengan rentang $0.1-2 \mathrm{~m} / \mathrm{s}$ dengan arah pola arus ke arah timur tetapi dominan ke arah barat, pantai Bemban kecepatan rentang antara 0.02-0.44 m/s dengan pola arus ke arah utara tetapi dominan ke arah barat, pantai Payung kecepatan arus dengan rentang antara 1.7 -1.8 dominan ke arah barat. Pasang surut pantai bemban menunjukkan pasang surut semi diurnal menunjukkan pasang tertinggi dua kali dan paanngg surut terendah dua kali. Tumbuhan Lamun yang diidentifikasi melalui dari citra satelit dengan algoritma Lyzenga terdapat di pantai Payung, untuk pantai Nongsa dan Bemban belum dapat mengidentifasi klorofil-a melalui citra satelit. Suhu dan DO yang terdapat dari tiga lokasi setelah di rata-ratakan menunjukkan suhu $29-32{ }^{\circ} \mathrm{C}$ dan DO $12.5-27.5 \mathrm{mg} / \mathrm{L}$.
\end{abstract}

Keywords: Pasang Surut, Arus, Suhu, Dissolve Oxygen (DO)

\begin{abstract}
Oceanographic parameters are the natural dynamics that occur affect the physics point of sea water, such as temperature, tides and currents. This study took samples in the territorial waters of Nongsa, then do the processing of data with remote sensing algorithms using Lyzenga and take the primary data of temperature, DO, the flow pattern in the form of currents, tides are presented in graphical form. Results in the field get the velocity at Nongsa coast with a speed range of $0.1-2 \mathrm{~m} / \mathrm{s}$ with the direction of flow pattern eastward but the dominant westward, the coast Bemban speed ranges between 0.02 to $0.44 \mathrm{~m} / \mathrm{s}$ with a flow pattern in the direction but the dominant north-west, beach Payung current speed with a range between $1.7-1.8$ dominant westward. Tidal beach Bemban show semi-diurnal tides twice showed the highest tide and low tide twice. Seagrass plants were identified through satellite imagery with Lyzenga algorithms contained on the beach Payung, to the beach and Bemban Nongsa can not identification chlorophyll-a by satellite imagery. Temperature and DO contained in three locations after the show averaged temperature $29-32^{\circ} \mathrm{C}$ and DO $12.5-27.5 \mathrm{mg} / \mathrm{L}$.
\end{abstract}

Keywords: Tidal, Current, Temperature, Dissolve Oxygen (DO)

\section{Pendahuluan}

Perairan Pulau Batam memiliki kondisi yang strategis dengan jalur lintas internasional dan pesatnya perkembangan industri skala besar dan kecil. Namun seiring perkembangannya akan mempengaruhi kondisi perairan dan ekosistem di dalamnya.
Pulau Batam berkembang menjadi daerah industri, perdagangan, alih kapal dan pariwisata yang menarik wisatawan lokal dan asing serta investor asing banyak melakukan investasi dan membuka lapangan pekerjaan di Batam, walaupun Batam dikenal sebagai kota industri secara administratif Batam terdiri dari darat dan pesisir laut. Tinggginya aktivitas manusia menyebabkan tingginya bahan pencemar yang ada pada lingkungan perairan pesisir Batam berbagai 
aktivitas manusia di main landbaik indutsri, hotel, dan pusat ekonomi serta aktivitas hinterland baik itu pelayaran, pencemaran minyak, dan galangan kapal [1].

Nongsa sebagai obyek kajian dikarenakan kawasan Nongsa, kawasan yang sedang berkembang di Pulau Batam juga terdapat sejarah yang menarik di daerah ini, dimana terdapat Nongsa Isa merupakan penduduk asli Batam sehingga saat ini dikenal sebagai pantai Nongsa yang dahulu Nongsa dikenal sebagai pelabuhan untuk menuju ke negara Singapura dan Semenanjung Malaysia [2].

Penelitian yang telah dilaksanakan oleh Rahayu Kusuma Risdianto dan Undang Hernawan pada tahun 2013 , Rahayu dan Undang melakukan Penelitian yang berjudul “ Indeks Kualitas Lingkungan di Wilayah perairan di Natuna Terkait dengan Industri Migas" Metode yang dilakukan pengambilan titik sampel sebanyak 15 titik . Data digunakan sebagai parameter yaitu suhu, kekeruhan, Massa Padatan Tersuspensi, Disslove Oxygen (DO), Biological Oxygen Demand (BOD), Fosfat, Nitrat, dan Ph . Hasil dari penelitian Distribusi Kualitas Lingkungan menunjukkan kategori sangat baik $\left(6.518,11 \mathrm{~km}^{2} \mathrm{atau}\right.$ $26,62 \%$ ) baik $\left(17.753,04 \mathrm{~km}^{2}\right.$ atau $\left.72,43 \%\right)$ dan cukup baik $\left(232,61 \mathrm{~km}^{2}\right.$ atau $\left.0,95 \%\right)$ dari total luasan sebesar wilayah studi sebesar $24.485 \mathrm{~km}^{2}$. Secara umum perairan laut Natuna yang dikaji masih dalam kondisi baik [3].

Klorofil merupakan parameter dalam menentukan produktivitas primer di laut, hal ini terdapat sebaran rendah dan tinggi terkait dengan kondisi oseanografi suatu perairan [4]. Klorofil sendiri terbagi tiga jenis, yaitu klorofil-a,b, dan c. Klorofil sangat penting dalam proses fotosintesis tumbuhan kandungan klorofil dominan dimiliki oleh fitoplankton yaitu klorofil-a . oleh karena itu klorofil-a dikatakan salah satu indikator suburnya perairan [5]. Manfaat dari Klorofil-A cukup banyak, klorofil -A merupakan tumbuhan yang terdapat di laut seperti alga,lamun, ataupun rumput laut,rumput laut (Seaweed) bermanfaat bagi kesehatan dikarenakan kandungan dalam rumput laut dapat mencegah dari penyakit dapat dikembangkan dan dibudidayakan untuk Industri di Indonesia [6].

Penginderaan jauh diambil sebagai alternatif untuk melihat kondisi perairam di Pulau Batam dengan pengambilan lokasi di Nongsa sebagai sampelnya , dalam penelitian menggunakan algoritma Lyzenga seolah-olah melakukan pemisahan antara daratan dan lautan untuk mendeteksi habitat perairan dangkal di perairan Nongsa

\subsection{Tujuan}

Penelitian ini untuk melihat kondisi oseanografi di perairan Nongsa dengan memanfaatkan pengambilan data primer dan data sekunder yang di dapat dari citra landsat 8 untuk melihat perairan dangkal di lokasi tersebut, apakah mengalami kerusakan ataupun tidak.

\subsection{Daerah Penelitian}

Penelitian ini dilaksanakan di Perairan Nongsa di pantai Nongsa, pantai Bemban dan pantai Payung, pengumpulan data primer yakni Pasang surut, Arus , Suhu, dan DO dan data sekunder untuk melihat klorofil-a di daerah tersebut.

\section{Metode Penelitian}

\subsection{Lokasi Penelitian}

Kegiatan Penelitian dilaksanakan pada bulan Agustus hingga Desember 2016.Kegiatan pengambilan data dilaksanakan di Pulau Batam dengan sampel di Kecamatan Nongsa, koordinat lokasi Penelitian 1 02'44" LU 104 01' BT, waktu Perekaman: dimulai 5 Juli, waktu Pengolahan: 2 bulan (Juli-September 2016). Gambar Peta penelitian dapat dilihat pada Gambar 1.

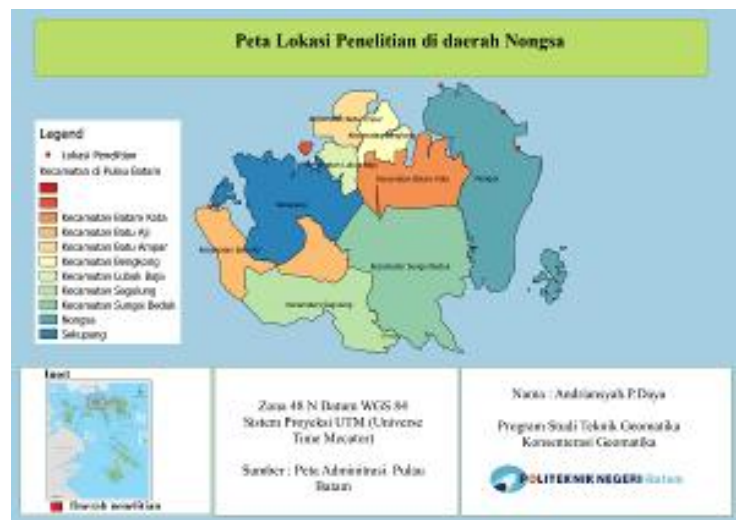

Gambar 1. Peta Lokasi penelitian

\subsection{Metode Langrangian}

Metode ini dipakai untuk mengambil data arus laut dengan selang waktu selama 30 detik, data menunjukkan perairan pola arus dominan ke arah barat.

\section{Algoritma Lyzenga}

Algoritma ini untuk melihat perairan dangkal di perairan Nongsa,seperti Lamun,terumbu karang, alga dan lain-lain. Formula oleh [7] yaitu sebagai berikut:

$\mathrm{Y}=\mathrm{Ln}(\mathrm{TM} 1)+\mathrm{ki} / \mathrm{kj} \mathrm{Ln}(\mathrm{TM} 2)$

\section{Keterangan:}

Y: Ekstraksi informasi dasar

TM1: Kanal 1

TM2: Kanal 2

$\mathrm{ki} / \mathrm{kj}$ : koefisien atenuasi

\subsection{Alat dan Bahan}

Alat yang digunakan adalah Theodolit,rambu ukur, DO meter untuk mengukur Arus laut, pasang surut , DO dan suhu. Bahan yang digunakan adalah Citra 
Landsat 8 dan data primer hasil pengukuran di Lapangan yang kemudian dioalah.

\subsection{Proses Pengolahan di Citra Landsat 8}

1. Mengunduh citra landsat 8 level (peta dasar)

2. Melakukan Koreksi Geometrik dan Radiometrik

3. Sesuaikan RMS $<1$, jika tidak sesuai kembali ke koreksi.

4. Lakukan Cropping area yang dijadikan obyek penelitian.

5. Memasukkan Algortima Lyzenga, untuk melihat klorofil-a di pantai Nongsa, pantai Payung dan pantai Bemban.

6. Kemudian Ground Check Lapangan

\subsection{Proses Pengambilan data di Lapangan}

1. Menyiapkan alat-alat survey

2. Kemudian melakukan pengukuran lapangan untuk Arus, Pasang Surut, DO dan Suhu.

3. Kemudian pengumpulan data dan pengolahan untuk menjadi peta.

\subsection{Metode Klasifikasi}

Merupakan Metode yang dilakukan dalam mengklasifikasikan setiap peta yang telah diolah. Lalu hasil yang di dapatkan di citra dan algoritma lyzenga dapat di klasifikasikan serta Arus disajikan dalam bentuk Pola Arus dan Pasang Surut disajikan dalam bentuk Grafik.

\subsection{Koreksi Geometrik dan Radiometrik}

Pengolahan geometrik untuk mengetahui posisi citra yang sebenarnya dari citra dengan posisi sebenarnya dan koreksi radiometrik menghilangkan awan ataupun noise pada citra yang akan diolah.

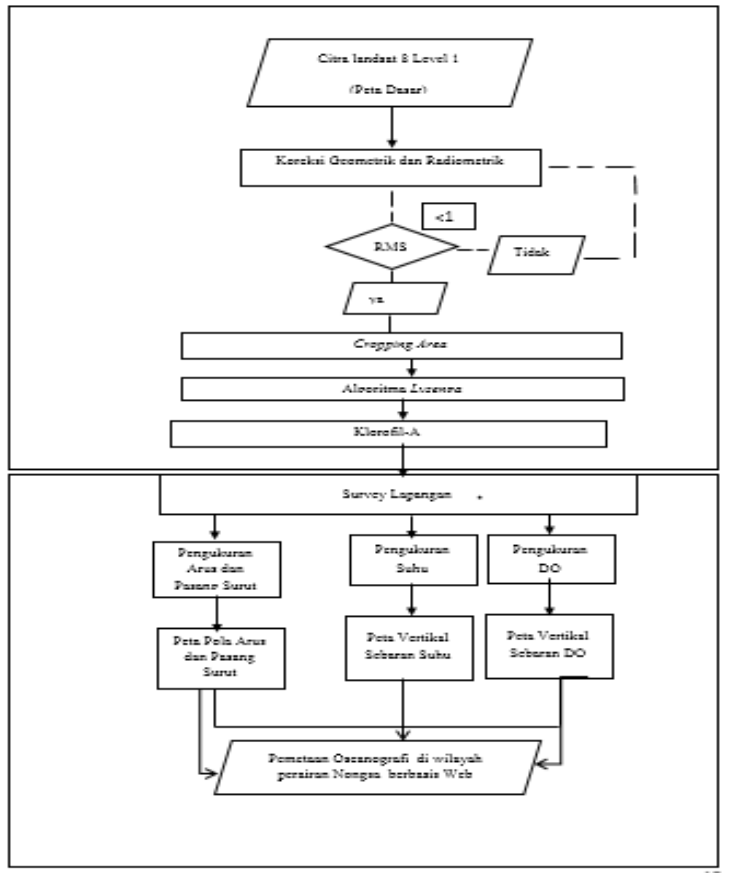

Gambar 2. Diagram Alir Penelitian

\section{Hasil dan Pembahasan}

Hasil pengolahan data yakni pola arus di perairan nongsa yang dominan ke arah barat dan barat laut.Pantai Nongsa menunjukkan pola arus menyebar mengarah ke barat laut dan dominan ke arah timur dikarenakan daerah tanjung yang merupakan pertemuan dua massa air besar dan menunujukkan pola arus menyebar, Kececepatan arus terbesar $2 \mathrm{~m} / \mathrm{s}$ dan kecepatan arus terkecil 0.1 $\mathrm{m} / \mathrm{s}$.

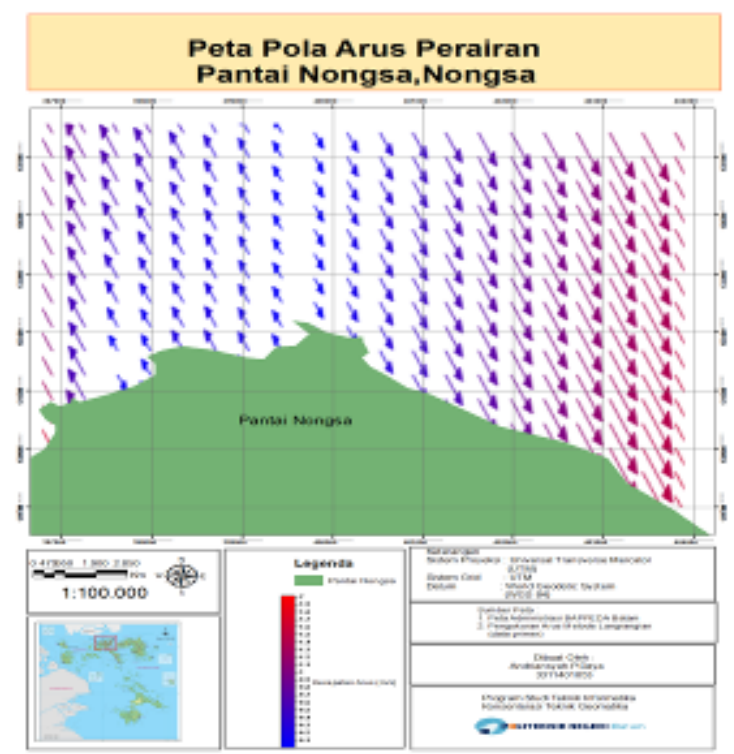

Gambar 3. Pola arus pantai nongsa

Pada Gambar 3, pantai Payung menunjukkan pola arus dominan mengarah ke barat laut., kecepatan arus terbesar $1.825 \mathrm{~m} / \mathrm{s}$ dan kecepatan arus terkecil 1.76 $\mathrm{m} / \mathrm{s}$. Lokasi pantai payung juga terdapat lamun merupakan tumbuhan di perairan dangkal yang dikategorikan sebagai klorofil -a.

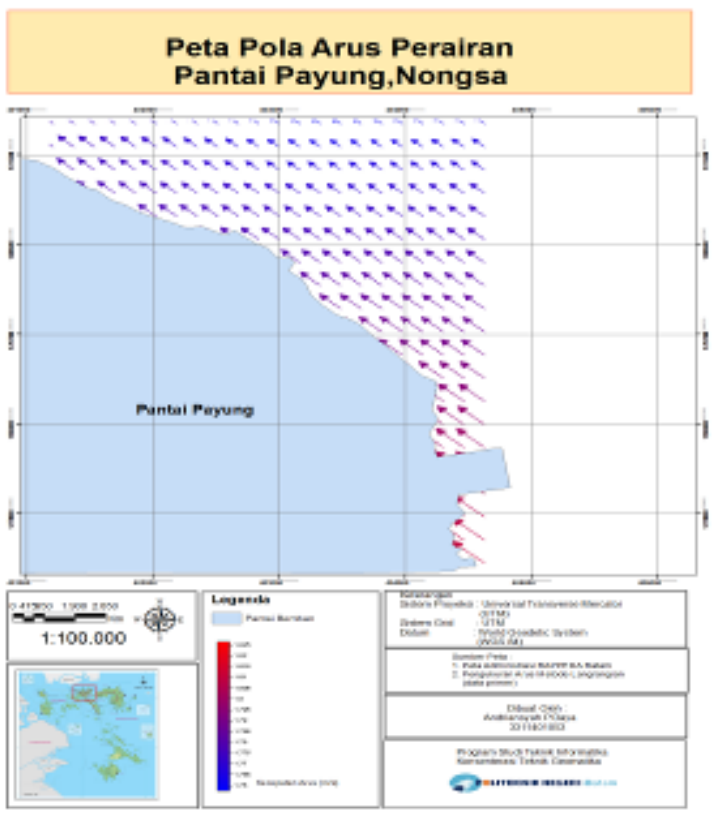

Gambar 4. Pola arus pantai payung 
Paga Gambar 4 terlihat jelas pantai Bemban menunjukkan pola arus menyebar mengarah ke barat laut dan timur, tetapi dominan ke arah barat laut,kecepatan arus terbesar pada $0.44 \mathrm{~m} / \mathrm{s}$ dan kecepatan arus terkecil $0.02 \mathrm{~m} / \mathrm{s}$.

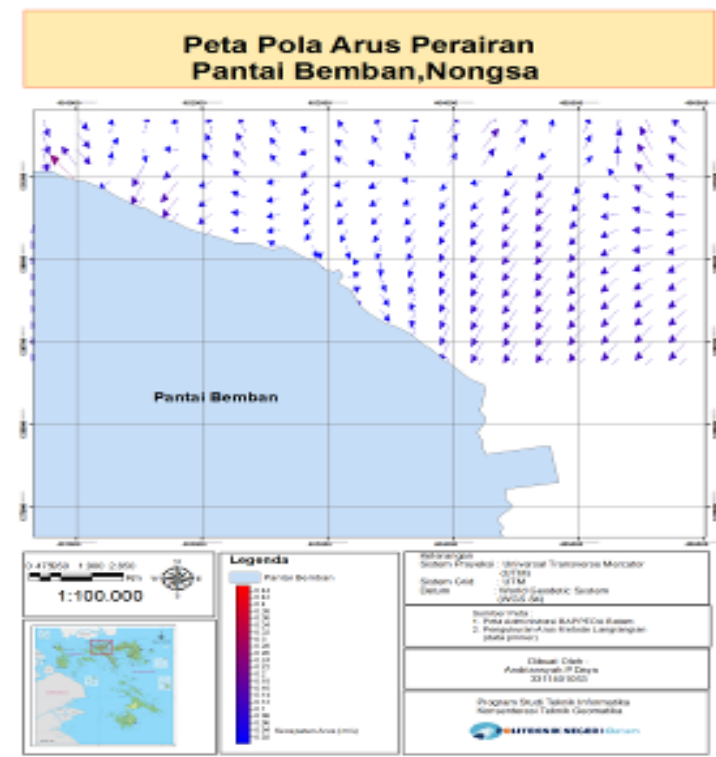

Gambar 5. Pola arus pantai bemban

Pengolahan data pasang surut di matlab menunjukkan hubungan waktu dan tingi muka air yang berlokasi di pantai Bemban dengan tipe pasang surut semi diurnal. Grafik Minggu 1

(Gambar 6)ditandai dengan warna merah dengan sumbu $\mathrm{x}$ menunjukkan waktu dan sumbu y menunjukkan Tinggi muka air, hasilnya pada sumbu x surut terendah pada jam 19.00 WIB dan 9.49 WIB dengan tinggu muka air $40 \mathrm{~cm}$ dan pasang tertinggi pada jam 23.45 WIB dan 12.45 WIB dengan tinggi muka air 200-250 cm dan 150-200 $\mathrm{cm}$.

Grafik Minggu 2 ditandai dengan warna biru dengan sumbu $\mathrm{x}$ menunjukkan waktu dan sumbu $\mathrm{y}$ menunjukkan Tinggi muka air, hasilnya pada sumbu $\mathrm{x}$ surut terendah pada jam 4. 45 WIB dan 10.00 WIB dengan tinggu muka air $45 \mathrm{~cm}$ dan pasang tertinggi pada jam 1.45 WIB dan 14.00 WIB dengan tinggi muka air $200-250 \mathrm{~cm}$.

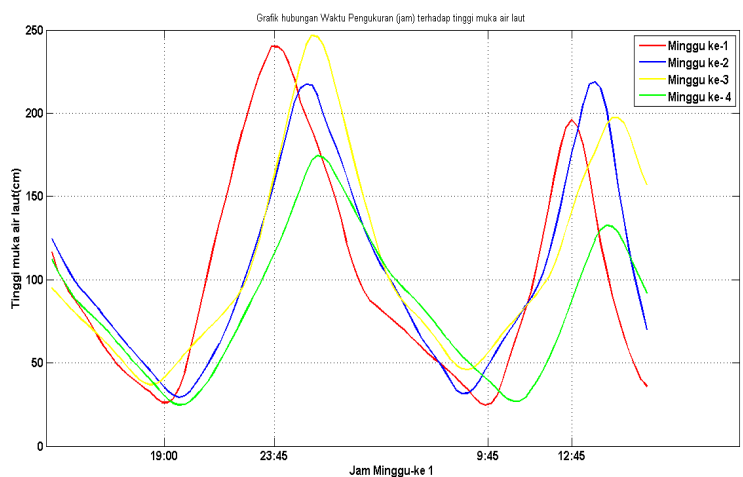

Gambar 6 grafik hubungan waktu terhadap tinggi muka air laut ke-1
Grafik Minggu 2 ( Gambar 7) ditandai dengan warna kuning dengan sumbu $\mathrm{x}$ menunjukkan waktu dan sumbu y menunjukkan Tinggi muka air, hasilnya pada sumbu $x$ surut terendah pada jam 4. 30 WIB dan 19.45 WIB dengan tinggu muka air $50 \mathrm{~cm}$ dan pasang tertinggi pada jam 1.15 WIB dan 14.30 WIB dengan tinggi muka air $200-250 \mathrm{~cm}$ dan $150-200 \mathrm{~cm}$.

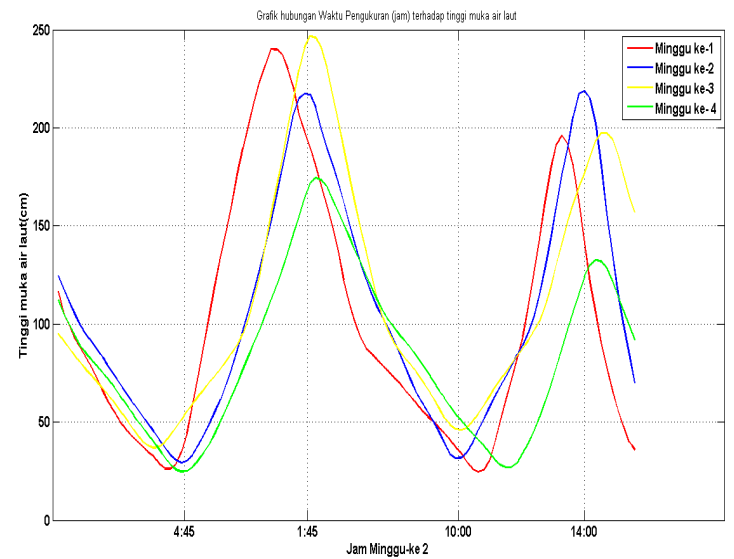

Gambar 7. Grafik hubungan waktu terhadap tinggi muka air laut ke -2

Grafik Minggu 3 ( Gambar 8) ditandai dengan warna kuning dengan sumbu $\mathrm{x}$ menunjukkan waktu dan sumbu y menunjukkan Tinggi muka air, hasilnya pada sumbu $x$ surut terendah pada jam 4. 30 WIB dan 19.45 WIB dengan tinggu muka air $50 \mathrm{~cm}$ dan pasang tertinggi pada jam 1.15 WIB dan 14.30 WIB dengan tinggi muka air $200-250 \mathrm{~cm}$ dan $150-200 \mathrm{~cm}$.

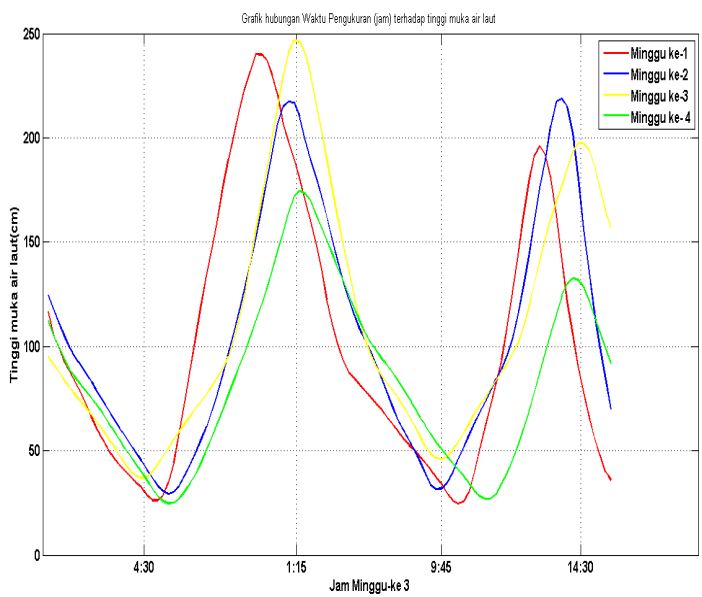

Gambar 8. Grafik hubungan waktu terhadap tinggi muka air laut ke -3

Grafik Minggu 4 ditandai dengan warna hijau dengan sumbu $\mathrm{x}$ menunjukkan waktu dan sumbu $\mathrm{y}$ menunjukkan Tinggi muka air, hasilnya pada sumbu $\mathrm{x}$ surut terendah pada jam 4. 45 WIB dan 10.00 WIB dengan tinggu muka air $45 \mathrm{~cm}$ dan pasang tertinggi pada jam 1.30 WIB dan 14.00 WIB dengan tinggi muka air $150-200 \mathrm{~cm}$ dan $100-150 \mathrm{~cm}$. 


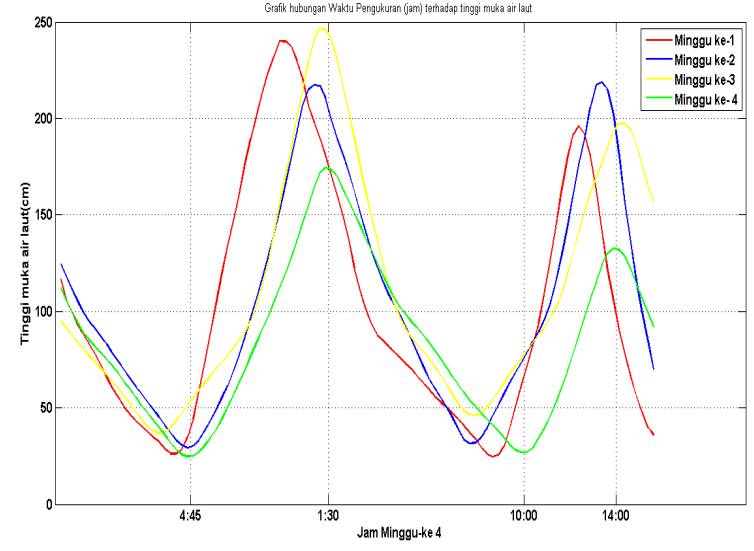

Gambar 9. Grafik hubungan waktu terhadap tinggi muka air laut ke -3

Berdasarkan data yang primer di dapatkan sebaran suhu dan DO yang telah di gabungkan dari tiga lokasi .Berdasarkan data primer yang telah di dapatkan di lapangan didapatkan hubungan antara dissolve oksigen (DO) dan pola arus suhu di daerah pantai Payung menunjukkan kandungan oksigen terlarut rentang antara 12.5-27.5 $\mathrm{mg} / \mathrm{L}$ dengan rata-rata kandungan oksigen terlarut 20-25 mg/Ldari ketiga pantai yang dibedakan dengan gradasi warna dimulai dari warna biru hingga merah dengan DO terbesar di Pantai Nongsa dengan 46.7 $\mathrm{mg} / \mathrm{L}$ dan pola arus pantai Payung dominan ke arah barat laut dengan koordinat 104.09 - 104.14 Bujur Timur dan 1.15 - (-1.19) Lintang Utara ( Gambar 10).

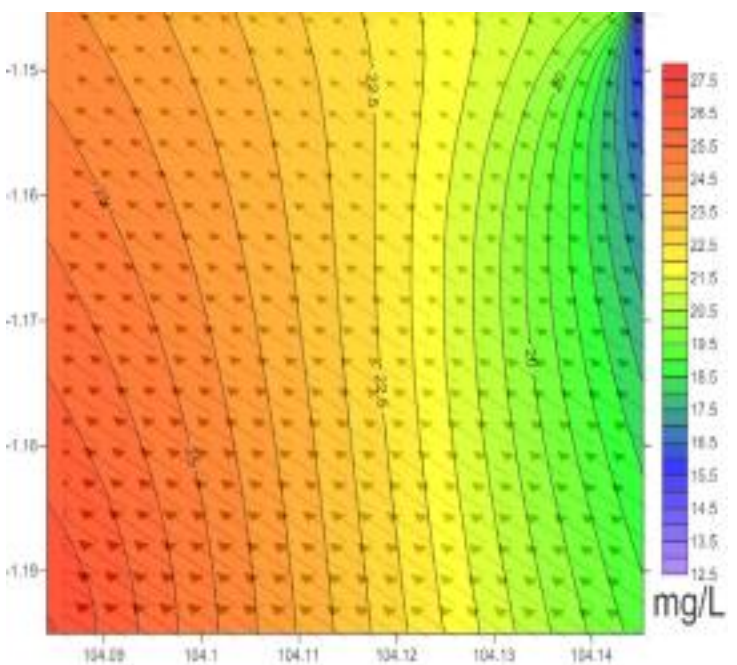

Gambar 10. Hubungan do terhadap arus pantai payung

Hubungan antara Suhu dan pola arus suhu di daerah pantai Payung menunjukkan kandungan Suhu rentang antara 29 - 32.6 dengan rata-rata kandungan suhu 30$31^{\circ} \mathrm{C}$ dari ketiga pantai yang dibedakan dengan gradasi warna dimulai dari warna biru hingga merah dengan Suhu terbesar di Pantai Payung dengan 36.4 ${ }^{\circ} \mathrm{C}$ dan pola arus pantai Payung dominan ke arah barat laut dengan koordinat 104.09 - 104.14 Bujur Timur dan $-1.15-(-1.19)$ Lintang Utara (Gambar 11).

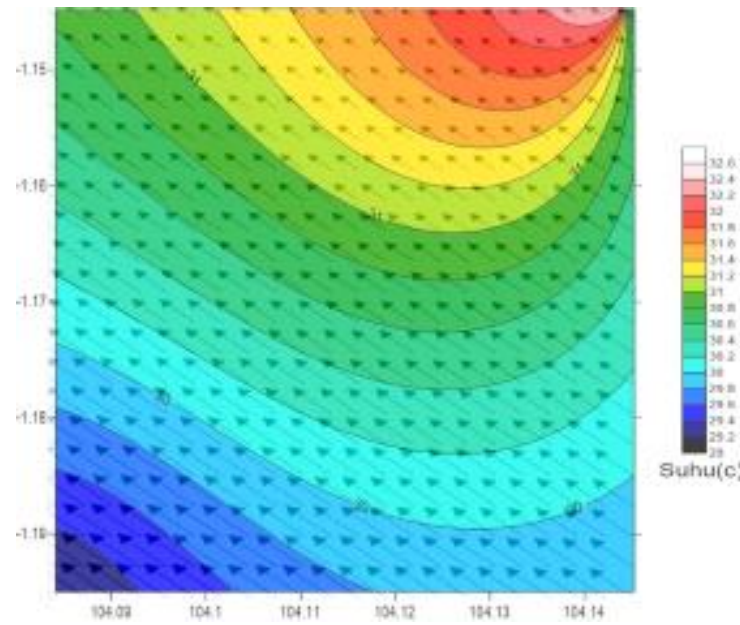

Gambar 11. Hubungan suhu terhadap arus pantai payung

Hubungan antara dissolve oksigen (DO) dan pola arus suhu di daerah pantai Nongsa menunjukkan kandungan oksigen terlarut rentang antara 12.5-27.5 $\mathrm{mg} / \mathrm{L}$ dengan rata-rata kandungan oksigen terlarut 20$25 \mathrm{mg} / \mathrm{L}$ dari ketiga pantai yang dibedakan dengan gradasi warna dimulai dari warna biru hingga merah dengan DO terbesar di Pantai Nongsa dengan 46.7 $\mathrm{mg} / \mathrm{L}$ dan pola arus pantai Nongsa menyebar ke arah barat laut dan dominan ke arah timur dengan koordinat 104.09 - 104.14 Bujur Timur dan -1.15 - (1.19) Lintang Utara (Gambar 12).

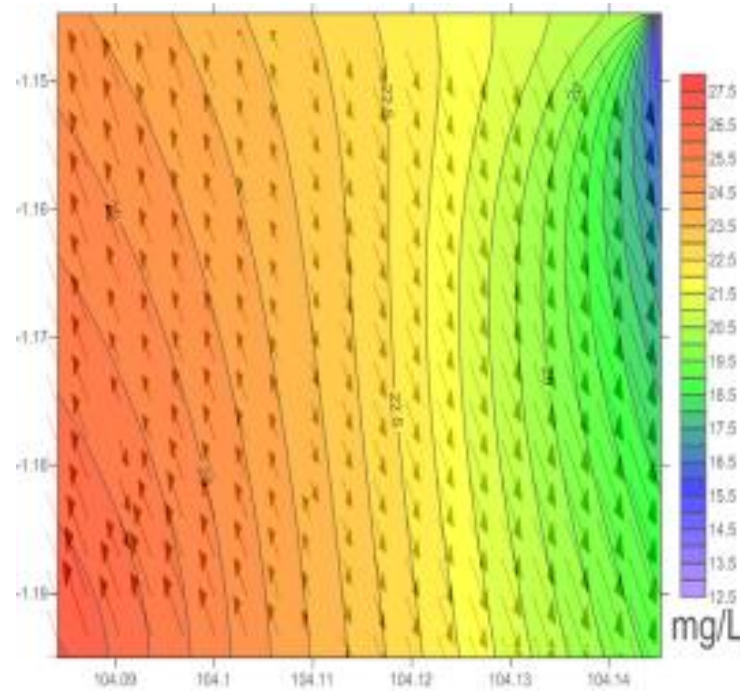

Gambar12. Hubungan DO terhadap arus pantai nongsa

Hubungan antara Suhu dan pola arus suhu di daerah pantai Nongsa menunjukkan kandungan Suhu rentang antara 29 - 32.6 dengan rata-rata kandungan suhu 30$31{ }^{\circ} \mathrm{C}$ dari ketiga pantai yang dibedakan dengan gradasi warna dimulai dari warna biru hingga merah dengan Suhu terbesar di Pantai Payung dengan 36.4 ${ }^{\circ} \mathrm{C}$ dan pola arus pantai Nongsa menyebar ke arah barat dan dominan ke arah timur dengan koordinat 104.09 - 104.14 Bujur Timur dan -1.15 - (-1.19) Lintang Utara (Gambar 13). 


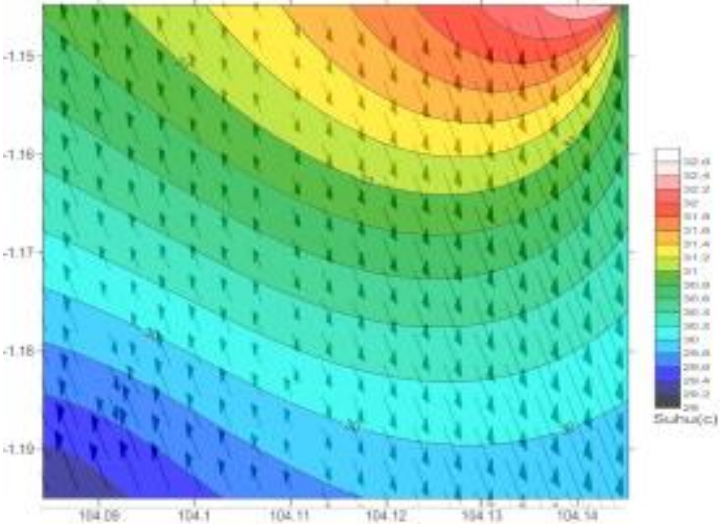

Gambar13. Hubungan suhu terhadap arus pantai nongsa

Hubungan antara dissolve oksigen (DO) dan pola arus suhu di daerah pantai Bemban menunjukkan kandungan oksigen terlarut rentang antara 12.5-27.5 $\mathrm{mg} / \mathrm{L}$ dengan rata-rata kandungan oksigen terlarut 20$25 \mathrm{mg} /$ Ldari ketiga pantai yang dibedakan dengan gradasi warna dimulai dari warna biru hingga merah dengan DO terbesar di Pantai Nongsa dengan 46.7 $\mathrm{mg} / \mathrm{L}$ dan pola arus pantai Bemban menyebar ke arah timur dan dominan ke arah barat laut dengan koordinat 104.09 - 104.14 Bujur Timur dan -1.15 - (1.19) Lintang Utara (Gambar 14).

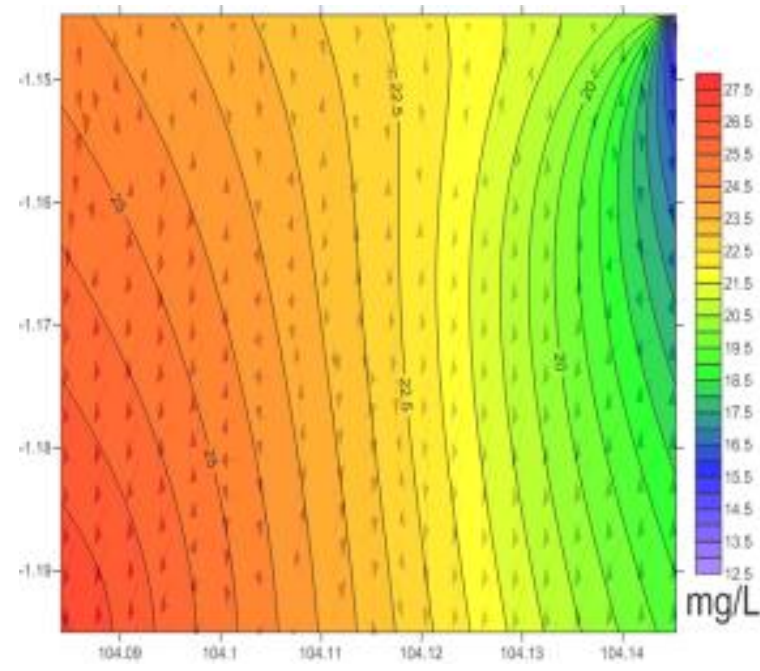

Gambar14. Hubungan DO terhadap arus pantai bemban

Hubungan antara Suhu dan pola arus suhu di daerah pantai Bemban menunjukkan kandungan suhu rentang antara 29 - 32.6 dengan rata-rata kandungan suhu 30$31^{\circ} \mathrm{C}$ dari ketiga pantai yang dibedakan dengan gradasi warna dimulai dari warna biru hingga merah dengan Suhu terbesar di Pantai Payung dengan 36.4 ${ }^{\circ} \mathrm{C}$ dan pola arus pantai Nongsa menyebar ke arah timur dan dominan ke arah barat laut dengan koordinat 104.09 - 104.14 Bujur Timur dan -1.15 - (1.19) Lintang Utara (Gambar 15).

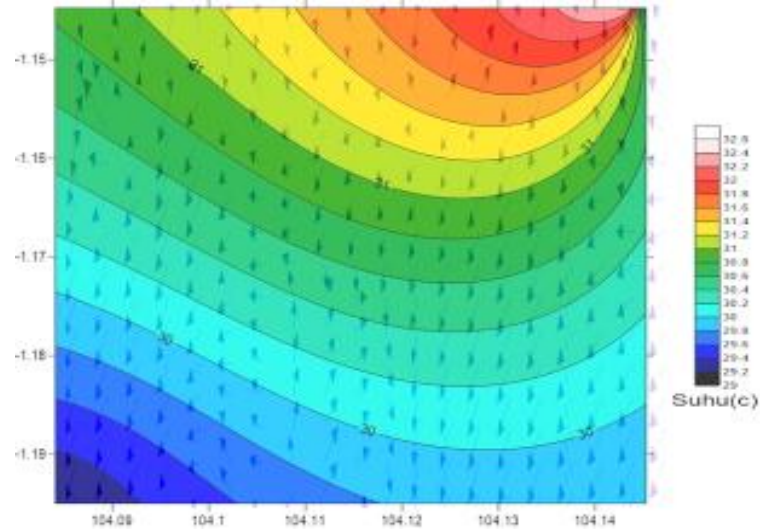

Gambar 15. Hubungan suhu terhadap arus pantai bemban

Berdasarkan data citra diperoleh hubungan pantai nongsa dan hasil pengolahan lyzenga, pola arus di pantai nongsa menyebar dengan adanya pola arus kearah barat dan ke arah timur dengan dominan kearah timuur (Gambar 16).

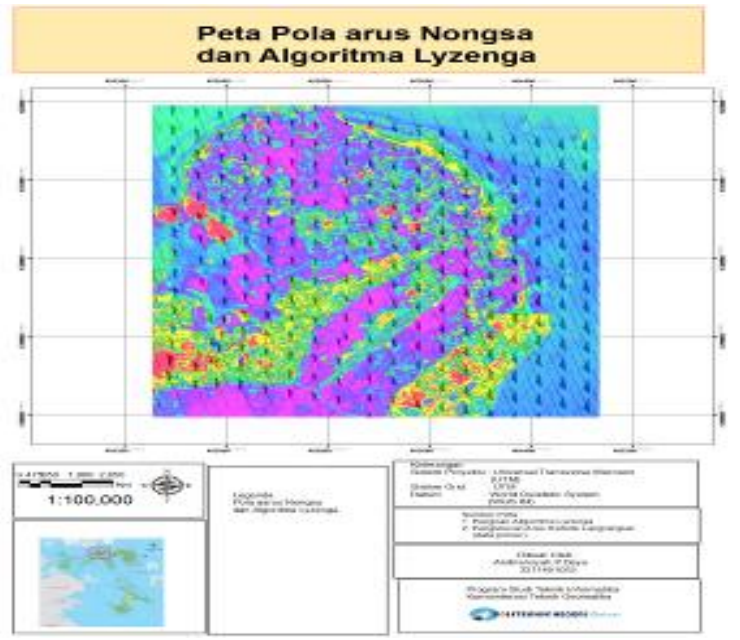

Gambar 16. Hubungan lyzenga terhadap pantai nongsa

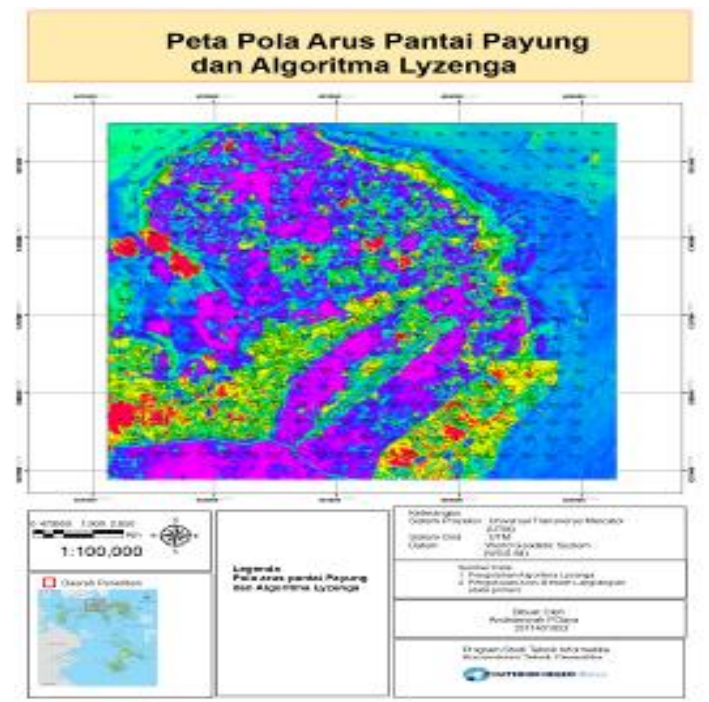

Gambar 17. Hubungan Lyzenga terhadap Pantai Payung 
Pada hasil hubungan pantai bemban dan hasil pengolahan lyzenga, pola arus di pantai payung menyebar dengan adanya pola arus dominan kearah barat laut, hal ini jelas terlihat pada Gambar 16, 17, dan 18 .

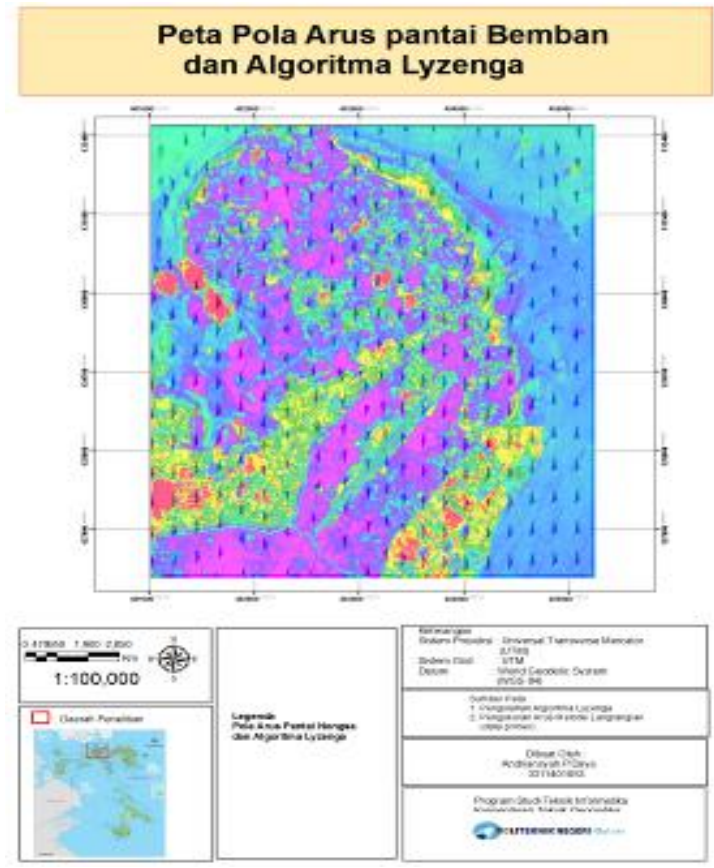

Gambar 18. Hubungan Lyzenga dengan Pantai Bemban

\section{Kesimpulan dan Saran}

\subsection{Kesimpulan}

Berdasarkan Data primer yang di dapatkan dilapangan yakni suhu di perairan Nongsa masih dikategorikan stabil juga dengan DO,Pasang Surut bertipe semi diurnal, dan Pola Arus dominan ke arah barat, untuk pengolahan citra dengan landsat 8 di dapatkan sebaran lamun di pantai Payung yang dikategorikan sebagai klorofil-a.

\subsection{Saran}

Sebaiknya pengukuran pasang surut dilakukan lebih banyak lagi untuk melihat variasi pasang surutnya dan pengolahan citra landsat juga melihat suhu dan DO .

\section{Daftar Pustaka}

[1] Firdaus, R.2016 "Pencemaran Perairan Pesisir Kota Batam dan Harapan Pengelolaan Lingkungan Hidup." Opini 1.4.

[2] Purwanti, A. 2016. Penataan Objek Wisata Sebagai Strategi Komunikasi Dinas Pariwisata dan Kebudayaan dalam Kegiatan Visit Batam 2010. Jurnal Komunikasi, 10(1), 29-40.
[3] Rusdiansyah, A. 2016. Pola Arus di Kolam Pasang Surut Akibat Pengaruh Angin. Iifo-Teknik, 7(1), 1-7.

[4] Mann, K. H., and J. R. N. Lazier. 1991. "Fronts in coastal waters." Dynamics of Marine Ecosystems, Third Edition : 216-253.

[5] Samawi, Muhammad Farid, and Dan Rahmadi Tambaru2011. Kualitas Karaginan Rumput Laut Jenis Eucheuma Spinosum di Perairan Desa Punaga Kabupaten Takalar. Diss.

[6] Sahri, A. 2009. Mengenal potensi rumput laut: kajian pemanfaatan sumber daya rumput laut dari aspek industri dan kesehatan. Majalah Ilmiah Sultan Agung, 44(118), 95-116.

[7] Lyzenga, R.D. 1985. Shallow Water Bathymetry Using Combined Lidar and Passive Multispectral Scanner Data. International Journal of Remote Sensing. Vol. 6 No.8 